\title{
Relationship between Personality Traits and Perception of Family Functioning among Unwed Pregnant Teenagers
}

\author{
Dr. Asma Perveen \\ Clinical psychologist, senior lecturer, Sultan Idris University of Education \\ Dr. Pau Kee \\ Senior lecturer, Sultan Idris University of Education \\ Dr. Hazalizah Bt Hamzah \\ Senior lecturer, Sultan Idris University of Education \\ Dr. Fauziah Binti Mohd Sa'ad \\ Senior lecturer. Sultan Idris University of Education. Malaysia \\ Miss Nurul Syakila Binti Mohmed Darussalam \\ Sultan Idris University of Education
}

*Corresponding Author: Dr. Asma Perveen, Clinical psychologist, senior lecturer, Sultan Idris University of Education

\begin{abstract}
Different personality traits may have influenced the perception of family functioning. The aim of this study was to examine the relationship between the personality traits and perception of family functioning among unwed pregnant teenagers. Pregnant teenagers $(N=60)$ from Baitul Ehsan and BaituIslah participated in this study. Their age (mean 17.30), mostly were first born in the family, (80\%) and belong to rural area (30\%) urban area (70\%), education were (70\%) primary (PMR) and (30\%) SPM schooling. The instrument to assess personality and family functioning were Eysenck's Personality Inventory and Self-report Family Inventory II. After data collection the results were analyzed using Pearson Correlation to find the relationship between personality traits and perception of family functioning among unwed pregnant teenagers. The study results revealed a significant negative correlation between personality traits and pregnancy adolescent's perception of their family functioning. The highest score on extraversion domain, having a significantly lower score on healthy family functioning. The results showed that personality traits are negatively significant with perception of family functioning. The results of this study emphasize the importance of personality traits and early relationship with the family and interaction of family play a significant role in support of teenager behavior. The results help us to highlight the personality traits and family awareness to increase healthy sexual behaviors among teenagers.
\end{abstract}

Keywords: Personality traits, family functioning, pregnancy teenagers, extraversion, neuroticism

\section{BACKGROUND OF STUDY}

Pregnancy among unwed teenagers is a serious reproductive health problem in developing countries like Malaysia. World Health Organization (WHO) reported that a large proportion from 14 million pregnancy teenagers is unwanted. It is also been estimated that about 4.4 million teenagers had an abortions. The health consequences of unwanted teenage pregnancy including pregnancy complications such as anaemia, obstructed labor, infant death and stillbirth and increased the risk of maternal death.

Teenagers represent about 20 percent of the 28 million populations in Malaysia (Department of Statistics Malaysia, 2011). Nowadays, unwed teenage pregnancy has become a very serious social problem in our community. Several studies have been conducted involving teenagers concerning pregnancy out of wedlock. Pregnancy among teenagers who are not getting married yet is more likely to be unintended and can have negative effects on both the pregnant teenagers and her child.

Khan et al (2015) reported that the problem of pregnant teenagers outside of marriage has reached worrying levels when 1,048 related cases was recorded from January to March 2013. It shows that average 12 teenagers will get pregnant without marriage per day. The number of teenage pregnancies 
keeps increasing by years and Teen Pregnancy Statistics Manual 2012 showed a sudden increase in the number of maternal deaths among teens. Division assistant deputy director of Family Health Development Malaysia revealed that many factors contributed to unwed teenage pregnancy and lack of parental guidance was identified as the root of the problem. The researcher suggested the factors contribute to sex behavior among adolescents must be identified to overcome the problems. (UNICEF 2012)

The concept of family functioning is synonymous with the quality of family life, including wellness, competence, strengths and weakness of the family. The family competency models such as the Beavers system model (Beavers \& Hampson, 2013), McMaster model and Circumplex model (Onyishi, 2013) assumed that negative behavior among the adolescents within the family caused by the poor family functioning. Shah (2015) found from the similar study that problematic family functioning could cause different relationship pattern in the family. Thus, the behaviors of family members and the interaction among family subsystems could explain the misbehavior of adolescents.

Furthermore, Pilecki (2014) said that the researchers seldom examine the family functioning from the adolescent's perspective. The perception of family functioning may be different within family members. In this research, the researcher used the personality traits as a measurement to the perception of adolescences toward their family functioning. Big Five personality traits and social support research showed that agreeableness, extraversion and neuroticism seem to be most strongly related to social support (Swickert, 2010). Family functioning is one of the social supports. This research needs to be conducted to examine the relationship between personality traits and perception of family functioning among unwed pregnancy teenagers.

\section{Problem Statement}

Nowadays, the rate of teenage pregnancy has been increased from year to year. The United Nations Children's Funds (UNICEF, 2008) reported that $10 \%$ to $40 \%$ of young unmarried girls have had an unintended pregnancy according to community studies. Some of the causes of early pregnancy among teenagers are lack of education, especially sexual education, poverty, undergraduate, or problem with their family. Family functioning is important to provide emotional and physical needs of children. Children from dysfunctional families are likely to think that their needs are not important. The limited guidance from the parents leads the teen girls to involve in teenage pregnancy.

\section{RESEARCH Question}

1. Is there a relationship between extraversion and perception of family functioning among unwed pregnant teenagers?

2. Is there a relationship between neuroticism and perception of family functioning among unwed pregnant teenagers?

\section{HYPOTHESES}

There is a significant negative correlation between extraversion and perception of family functioning among unwed pregnant teenagers.

There is a significant negative correlation between neuroticism and perception of family functioning among unwed pregnant teenagers.

\section{RESEARCH METHOD}

The researcher used a quantitative approach as a design in this research, by using the survey method to collect data from the participants. All the participants need to answer all the items in Eysenck's Personality Inventory (EPI) and Self-report Family Inventory version ii (SFI-II). There are 57 items of open ended questions in Eysenck's Personality Inventory and 36 items in

SFI-II. All the items in SFI-II responded, according to 5-point Likert Scale rating from 1 to 5. At a first stage, the researchers choose the inventory and a questionnaire that was suitable with the research's objective.

\section{Population And SAmple}

A sample for this study involved experienced pregnancy, teenagers who were living in woman shelters home. The researchers have managed to get the respondents from two shelter home, which are Baitul Ehsan shelter home at SabakBernam and BaitulIslah shelter home at Bukit Beruntung. 
Participants were selected randomly. Both shelter homes are located in Selangor. Baitul Ehsan was operated under the Selangor Islamic Religious Council (MAIS) while BaitulIslah was founded by the private persons. The sample consisted of 60 pregnant teenagers, $n=60$ from two women's shelter home. 30 respondents involved in this study were residents of Baitul Ehsan and another 30 respondents were residents of BaitulIslah. The guardian of both shelter homes chooses the respondents randomly and the respondents were willing to join this study.

\section{Procedures}

Firstly, the researcher filled the permission form from the Faculty of Education and Human Development (FPPM) before conducting the research. Then, the researcher found the contact person who handled the permission for conducting research. The researchers tried to call many women's shelter homes and choose the two shelter home because of the distance and easier to have the permission. Baitul Ehsan Centre needs the application form from the university while BaitulIslah Centre just needs to have an appointment with the founder.

The researcher, distributed the questionnaires, face to face and pencils after being approved by the shelter homes. The participants were given 15 to 30 minutes in response to the questionnaire. The participants were provided with the inform consent letter due to the privacy of the information. The respondents were chosen randomly by the guardian of the shelter homes. The instructions were given by the researchers to all the respondents.

After collecting the data, the results were analyzed by using statistical methods of descriptive and coefficient correlation

\section{RESUltS}

Table1. Respondent's Centre

\begin{tabular}{|l|l|}
\hline Name of Centre & $n$ \\
\hline Baitul Ehsan & 30 \\
\hline BaitulIslah & 30 \\
\hline Total & 60 \\
\hline
\end{tabular}

The respondents involved in this study were $60(n=60)$ unwed pregnancy teenagers. $30 \quad(n=30)$ respondents were from Baitul Ehsan Centre and another $30(n=30)$ were from BaitulIslah Centre.

Table2. Respondent's Age

\begin{tabular}{|l|l|l|}
\hline Age & $\mathrm{n}$ & Percent $(\%)$ \\
\hline 14 & 3 & 5.0 \\
\hline 15 & 4 & 6.7 \\
\hline 16 & 6 & 10.0 \\
\hline 17 & 17 & 28.3 \\
\hline 18 & 11 & 18.3 \\
\hline 19 & 19 & 31.7 \\
\hline Total & 60 & 100.0 \\
\hline
\end{tabular}

The age of the respondents was from 14 to 19 years old. The table number 2 above showed that the most respondents aged were 19 years old, which means that late teenager were highly involved in this social problem than early teen ager.

Table3. Respondent's Number of Siblings

\begin{tabular}{|l|l|}
\hline Number of Siblings & $\mathrm{n}$ \\
\hline 1 & 2 \\
\hline 2 & 4 \\
\hline 3 & 11 \\
\hline 4 & 13 \\
\hline 5 & 7 \\
\hline 6 & 10 \\
\hline 7 & 7 \\
\hline 8 & 2 \\
\hline 9 & 2 \\
\hline 10 & 1 \\
\hline 12 & 1 \\
\hline Total & 60 \\
\hline
\end{tabular}


Besides, the demographic information showed the number of siblings in a family to describe the family members and the family environment of the respondents. Two respondents who were involved in this social problem was the only child in their families and one respondent has 11 siblings. The higher respondents have four siblings which were 13 respondents.

Table4. Respondent's Living Area

\begin{tabular}{|c|l|}
\hline Living Area & $n$ \\
\hline Urban & 44 \\
\hline Rural & 16 \\
\hline Total & 60 \\
\hline
\end{tabular}

The different living area of the respondents could give the different environment, living cost and others. The table showed that most of the respondents are from urban areas which were 44 respondents and the rural area have only 16 respondents. It was because the urban area is more likely to expose the various crimes and social problems.

Table5. Marital Status of Respondent's Parent

\begin{tabular}{|l|l|}
\hline Parent's Marital Status & $n$ \\
\hline Married & 49 \\
\hline Separated & 1 \\
\hline Divorced & 8 \\
\hline Others & 2 \\
\hline Total & 60 \\
\hline
\end{tabular}

Moreover, the parent's marital status showed that most of the parent's respondents were married. One of the respondents has separated parents, 8 respondents have divorced parents and two respondents have the other cases of parental status like single parents.

Table6. Education Level of Respondents

\begin{tabular}{|l|l|l|}
\hline Education Level & $n$ & Percent $(\%)$ \\
\hline PMR & 32 & 53.3 \\
\hline SPM & 25 & 41.7 \\
\hline Diploma & 3 & 5.0 \\
\hline Total & 60 & 100.0 \\
\hline
\end{tabular}

The table number 6 showed the education level of the respondents. The number of respondents who had PMR certificate is higher than the Diploma certificates which were 32 respondents and three respondents.

\section{DESCRIPTIVE ANALYSIS OF THE VARIABLES}

From the table below, we can see that the mean of extraversion which is 36.17 is higher than the mean of neuroticism which is 33.08. However, the standard deviation of neuroticism is higher than extraversion.

Table7. Mean and Standard Deviation of Personality Traits

\begin{tabular}{|l|l|l|}
\hline & $M$ & $S D$ \\
\hline Extraversion & 36.17 & 2.66 \\
\hline Neuroticism & 33.08 & 3.80 \\
\hline Psychoticism & 23.40 & \\
\hline
\end{tabular}

Table8. Mean and Standard Deviation of Perception of Family Functioning Subscales

\begin{tabular}{|l|l|l|}
\hline & $M$ & $S D$ \\
\hline Health/Competence & 48.45 & 18.12 \\
\hline Conflict & 29.80 & 8.95 \\
\hline Cohesion & 12.78 & 5.19 \\
\hline Leadership & 6.47 & 2.86 \\
\hline Expressiveness & 12.07 & 4.80 \\
\hline
\end{tabular}

The mean of perception of family functioning is higher on competency and conflicts, which indicate the mostly participants were having disturb perception of their family functioning towards cohesion, 
expressiveness and leadership. From the table, we can see the mean and standard deviation from each subscale in perception of family functioning. Health/Competence has the highest both mean and standard deviation and leadership has both the lowest both mean and standard deviation.

Table9. Correlation between Extraversion, Neuroticism and Perception of Family Functioning

\begin{tabular}{|l|l|l|l|}
\hline & Extraversion & Neuroticism & Family functioning \\
\hline Extraversion & 1 & -.038 & $-.257^{*}$ \\
\hline Neuroticism & -.038 & 1 & -.094 \\
\hline Perception of Family & $-.257^{*}$ & -.094 & 1 \\
\hline Functioning & & & \\
\hline
\end{tabular}

Correlation is significant at the 0.05 level (one-tailed)

There is significant negative correlation between extraversion and perception of family functioning with statistical analysis $r(58)=-.257$ two tailed. Neuroticism negative correlation, $\mathrm{r}=-094$.

\section{DiscusSION}

The aim of this study was to examine the relationship between personality traits and perception of family functioning. Based on the findings, there is a significant negative correlation between extraversion and perception of family functioning while neuroticism showed no significant negative correlation with perception of family functioning. When the extraversion is high, perception of family functioning is low. Thus, the data showed there is a relationship between personality traits and perception of family functioning. Extraversion showed the significance value with Health/Competence and Cohesion and neuroticism showed no significance with any subscales of perception of family functioning.

In this study, the researcher focused on two types of personality traits which are extraversion and neuroticism. Personality traits are believed to have influences on social support (Saim, 2013). Extraversion and neuroticism are of particular interest because their brain bases might contribute to a predisposition to mood and anxiety disorders (Matthews, 2013). Jaccard (2009) on his book stated that extraversion and neuroticism are personality systems that incorporate notions of impulsivity, sociability and emotional stability

Costa and McCrae (1991) stated that neuroticism is the enduring tendency to experience negative emotional states and extraversion is the tendency to seek an excitement, challenges and to be assertive. The first hypothesis is supported by the previous research by Rhonda J. Swickert, (2010). It was stated that individuals who are extroverted enjoy being around others and have many friends. One of the studies that was conducted to investigate the relationship between personality and perceived social support, it found that individuals high in extraversion and agreeableness but low neuroticism have higher levels of perceived social support.

\section{REFERENCES}

[1] Beavers, R., \& Hampson, R. B. (2000). The Beavers System Model of Family Functioning. Journal of Family Therapy, 22, 128-143.

[2] Costa, P. T., Jr, \& McCrae, R. R. (1980). Influence of extraversion and neuroticism on subjective wellbeing: Happy and unhappy people. Journal of Personality and Social Psychology, 38(4), 668-678.

[3] Department of Statistics Malaysia. (2011). Population distribution and basic demography characteristics 2010. Kuala Lumpur: Department of Statistics Malaysia. Functioning. Journal of Family Therapy, 22, 128-143.

[4] Jaccard, J. (2009). Unlocking the Contraception Conundrum: Reducing Unplanned Pregnancies in Emerging Adulthood. Washington, DC: The National Campaign to Prevent Teen and Unplanned Pregnancy

[5] Khan AA, Jacobson KC, Gardner CO, Prescott CA, Kendler KS. 2015. Personality and comorbidity of common psychiatric disorders. Br J Psychiatry.

[6] Kingdom: Cambridge University Press.

[7] Matthews, G., Deary, I. J., \& Whiteman, M. C. (2003). Personality Traits. United Kingdom: Cambridge University Press.

[8] Onyishi, I. E., Okongwu, O. E., \& Ugwu, F. O. (2013). Personality and Social Support as Predictors of Life Satisfaction of Nigerian Prisons Officers. Europian Scientific Journal, 8(20), 110-125. 
[9] Pilecki, M.W.,Jozefik, B.\& Salapa, K. (2014). Correlations between the Perception of Family Functioning by Patients with Eating Disorders and Their Parents and the Perception of Relations in The Parents' Families of Origin. Psychiatria Polska, 48(4), 789-808.

[10] Saim, N. J., Dufaker, M., Eriksson, M., \& Ghazinour, M. (2013). Listen to the Voices of Unwed Teenage Mothers in Malaysian Shelter. Global Journal of Health Science; , 5(5), 20-30.

[11] Shah, A. (2014, January 14). More Unwed Teen Pregnancies. New Straits Time.

[12] Retrieved from http://www.nst.com.my/nation/general/more-unwed-teen-pregnancies-1.461045 \#ixz z2q JVx7Sqs

[13] Swickert, R.J., Hittner, J. B., \& Foster, A. (2010). Big Five Traits Interact to Predict Perceived Social Support. Personality and Individual Differences, 736-741.

[14] Swickert, R.J., Hittner, J. B., \& Foster, A. (2010). Big Five Traits Interact to Predict Perceived Social Support. Personality and Individual Differences, 736-741.

[15] UNICEF. (2012). Young People and Family Planning: Teenage Pregnancy. Malaysia: UNICEF.

[16] World Health Organization. (2000) Adolescent Sexuality and Reproductive Health Training Manual and Facilitator's Guide. WHO /FMSH /UNFPA 1999, 16-

Citation: Dr. Asma Perveen, et al., "Relationship between Personality Traits and Perception of Family Functioning among Unwed Pregnant Teenagers" International Journal of Humanities Social Sciences and Education (IJHSSE) vol 4, no. 9, 2017, pp. 40-45. doi:dx. doi.org/10.20431/2349-0381.0409006.

Copyright: () 2017 Authors. This is an open-access article distributed under the terms of the Creative Commons Attribution License, which permits unrestricted use, distribution, and reproduction in any medium, provided the original author and source are credited. 